\title{
Crisis sanitaria y el derecho fundamental a una buena administración pública: caso de los registros jurídicos en el Perú
}

\author{
Mg. Hidelbrando Jiménez Saavedra* \\ Universidad Privada Norbert Wiener \\ hidelbrando.jimenez@gmail.com \\ Código ORCID: https://orcid.org/0000-0002-9587-2471
}

\section{Resumen:}

El presente artículo busca comprender los efectos administrativos de la pandemia y la necesidad de regular el derecho fundamental a una buena Administración Pública. La investigación se aborda con enfoque cualitativo o hermenéutico utilizando el análisis de los hallazgos y de la triangulación de metodologías para validez y confiabilidad de resultados que han posibilitado generar opiniones y conclusiones. En efecto, se ha logrado establecer una perspectiva distinta del problema sanitario estimando sus efectos sobre la gestión pública, así como afirmar la necesidad de la regulación integral de los derechos dispersos de naturaleza administrativa que puedan integrar una buena administración pública como derecho fundamental.

En tal sentido, en el contenido del presente trabajo se describen los orígenes, evolución y los múltiples efectos de la pandemia en la sociedad peruana, específicamente los efectos administrativos. Asimismo, se parte de la necesidad de competitividad y gobierno digital como presupuestos y condición para una buena Administración Pública, sin descuidar los derechos subjetivos que dicho derecho fundamental alcanza. En el mismo sentido, se analiza el caso del sistema de los registros jurídicos en el Perú.

Palabras clave: crisis sanitaria; gestión pública; ciudadanía digital; seguridad jurídica; registros jurídicos

\section{Abstract:}

"Sanitary crisis and the fundamental right to good public administration: case of legal registries in Peru". This article seeks to understand the administrative effects of the pandemic and the need to regulate the fundamental right to good Public Administration. The research is led by a qualitative or hermeneutical approach and uses analysis of findings and triangulation of methodologies for validity and reliability of the results, results that have made it possible to generate opinions and conclusions. A different perspective of the health problem has been established estimating its effects on public management,

\footnotetext{
* Doctorando en Gobierno y Políticas Públicas por la Universidad Nacional de Ingeniería (UNI) y en el programa de Doctorado de en Derechos Fundamentales de la Universidad Norbert Wiener (UW). Magister en Gerencia Pública por la UNI. Abogado por la Universidad San Martín de Porres (USMP). Se desempeña desde el 2005 como Registrador Público de la Gerencia de Personas Jurídicas y Naturales de la Oficina Registral de Lima. Docente universitario.
} 
as well as affirming the need for comprehensive regulation of dispersed rights of an administrative nature that they can integrate good public administration as a fundamental right.

In that sense, in the content of the present work the origins are described, evolution and the multiple effects of the pandemic in Peruvian society, specifically administrative effects. Likewise, be part of the need for competitiveness and digital government as budgets and conditions for a good Public Administration, without neglecting the subjective rights that this fundamental right achieves. In the same way, the case of the legal records system in Peru is analyzed.

Keywords: health crisis; public management; digital citizenship; legal security; legal records

Recibido: 08.10.2020

Aceptado: 09.12.2020 


\section{Introducción}

El presente artículo busca comprender los efectos administrativos de la pandemia y, desde tal cometido, la necesidad de regular una buena Administración Pública para integrarla como derecho fundamental. Del mismo modo, desde la perspectiva de una buena Administración Pública, tiene por objeto analizar la performance y exigencia de mayor competitividad del Sistema Registral y de su Órgano de gestión frente a esta situación de emergencia, como parte de la Administración Pública peruana. En este aspecto, se analizará la necesidad de políticas públicas que orienten su accionar hacia nuevos horizontes registrales considerando las potencialidades del gobierno digital. Todo ello partiendo de la definición del registro como asegurador de los derechos de propiedad, institución pilar de la medición de la productividad o competitividad de un país.

Un aspecto que no puede omitirse en esta situación de pandemia es la íntima relación que se ha establecido entre Administración Pública, competitividad y gobierno digital. En efecto, la gestión de los diferentes servicios públicos se ha visto potenciada por la intervención del Gobierno mediante tales herramientas. Hasta los primeros meses del presente año, el gobierno digital en el país se consolidaba con la dación del Decreto Legislativo $\mathrm{N}^{\circ} 1412$, la puesta en marcha de la plataforma digital gob.pe para la Administración Pública como único acceso virtual, la creación del sistema nacional de transformación digital y la aprobación del marco de confianza digital (D.U 006 y 0072020). En tal sentido, la competitividad y la recuperación del crecimiento a los niveles de años anteriores parecían asegurados. Dos meses después de las últimas normas referidas se anunciaba y disponía el inicio de la emergencia sanitaria y días más una cuarentena a nivel nacional de la que se viene saliendo de modo focalizado y por etapas. La exigencia de mayores niveles de competitividad o productividad previstos para la Administración Pública se vieron incrementados con el fin de recuperar los recursos destinados a atender la situación generada por un virus atípico. En este contexto adquiere nivel de urgencia recurrir al gobierno digital para atender los diferentes servicios públicos.

El trabajo, desde un enfoque cualitativo, constituye el resultado hermenéutico y de triangulación de hallazgos, doctrina fundamentada, normas aplicables nacionales y de Derecho comparado. En esta línea se desarrolla el origen, evolución y efectos de la crisis sanitaria; un segundo apartado trata sobre la buena Administración Pública desde una perspectiva competitiva apoyada por el gobierno digital y de la necesidad de incorporarla como derecho fundamental. Esta visión nutre el último apartado que comprende la gestión de los Registros jurídicos en el Perú como integrante de la Administración Pública peruana. El desarrollo del trabajo permite establecer algunas conclusiones que responden al problema y propósito formulados.

\section{Crisis sanitaria}

\subsection{Orígenes}

Los virus, su estudio y tratamiento no resultan novedosos a nivel mundial, desde el primero descubierto y denominado virus del mosaico del tabaco por Martinus Beijerinck en 1899. Producen enfermedades infecciosas emergentes y reemergentes, que se constituyen en desafíos para la salud pública desde el Estado y su Administración.

La Organización Mundial de la Salud (Organización Mundial de la Salud [OMS], 2020) informa que fue en Wuhan, China, en donde se produce el descubrimiento de un 
nuevo tipo de Coronavirus (2019-nCoV). China lo dio a conocer oficialmente el 31 de diciembre de 2019. Se conocían 36 coronavirus. Los virus de la familia coronaviridae, conocidos como coronavirus, se tratan de virus de RNA envueltos que pueden encontrarse en humanos, mamíferos y aves, produciendo enfermedades respiratorias, hepáticas, neurológicas y entéricas. Se encontró que un $66 \%$ de pacientes (27 pacientes) -prevalentemente masculinos con edad promedio de 49 años - tenía contacto directo con un gran mercado de mariscos y animales que pudieron causar el primer brote. Los síntomas importantes de 2019-nCoV son: fiebre (98\%), tos seca $(76 \%)$, disnea $(55 \%)$, mialgia o fatiga (44\%) y linfopenia (63\%). Se conocen seis especies de Coronavirus que generan enfermedades en humanos. De estas solo dos especies -SARS-CoV y MERS-CoV- causan síndrome respiratorio agudo severo con efectos mortales en alto grado.

El 06 de marzo de 2020 se anuncia el primer caso de COVID-19 en Perú y el 16 del mismo mes y año se produce y anuncia la primera muerte. Ello coincide con el inicio de la cuarentena general y obligatoria a nivel nacional y con el desenlace de una serie de intervenciones desde el Poder Ejecutivo. El Banco Mundial (Banco Mundial, 2020) en su informe semestral de abril para la Región América Latina y El Caribe precisó que las "medidas generales de contención siempre conducen a un menor número de casos de COVID-19 que las medidas dirigidas. Pero ambas son considerablemente más efectivas si se adoptan inmediatamente después de que se registre el primer caso". En tal sentido se aprecian las intervenciones desde el Gobierno del Perú.

\subsection{Evolución - Estado actual}

La situación de pandemia (Organización Mundial de la Salud, 2020) es declarada por la Organización Mundial de la Salud (OMS) luego de verificar que en más de cien países del mundo se había extendido simultáneamente. Inmediatamente, el mismo 11 de marzo de 2020 de la declaración de la OMS, el Poder Ejecutivo expide el Decreto Supremo $\mathrm{N}^{\circ}$ 008-2020-SA, basado fundamentalmente en el Decreto Legislativo $\mathrm{N}^{\circ}$ 1156, y su Decreto Supremo reglamentario 007-2014-SA, declarando la Emergencia Sanitaria a nivel nacional por el plazo de noventa (90) días según calendario estableciendo. Adicionalmente, brinda medidas de prevención y control del COVID-19, medida que es ampliada por el mismo plazo por Decreto Supremo $N^{\circ} 020-2020-S A$ del 04 de junio de 2020.

El fundamento jurídico de la medida mencionada parte de la protección de la salud como derecho de los ciudadanos y obligación del Estado. Así, se regula desde el nivel constitucional en los artículos 7 y 9 de la Constitución Política vigente, desarrollándose éste desde la Ley General de Salud № 26842. Más aún se precisa el sistema funcional encargado de la gestión de las políticas públicas en salud como herramientas de gestión establecidas en el Decreto legislativo 1161. En tal sentido, corresponde al Ministerio de Salud liderar a nivel nacional lo concerniente a la emergencia sanitaria desde las funciones normativas, de gestión y supervisión, como responsabilidad del Estado para el impacto negativo de la pandemia.

El 15 de marzo de 2020, no obstante, con la declaración de emergencia sanitaria, el Poder Ejecutivo expide el Decreto Supremo N ${ }^{\circ}$ 044-2020-PCM, declarando el estado de emergencia a nivel nacional por quince días estableciendo la cuarentena, las restricciones a derechos fundamentales y las medidas preventivas, las que se han prorrogado hasta el 30 de junio de 2020. A partir del 01 de julio de 2020, mediante el Decreto Supremo $N^{\circ} 116-2020-\mathrm{PCM}$, se focaliza la cuarentena y se prorroga hasta el 31 de julio 2020, que es cuando se levantan las restricciones establecidas como efecto de la cuarentena. En suma, fueron 107 días de cuarentena generalizada lo que motivó 
un plan de reactivación económica en etapas durante la misma. Iniciamos esta etapa con índices presentados desde el Ejecutivo, precisándose al 01 de julio de 2020 que de los 282,365 casos positivos de COVID-19 en el país, 171,159 se encuentran recuperados y 101,000 activos. Las personas que superaron la enfermedad alcanzan un $63 \%$ frente al $37 \%$ que aún continúa con ella, cifras a las que se le añaden 9860 fallecidos. Los resultados de focalizar la cuarentena, si bien son los esperados, continúan desbordando los servicios de salud y afectando a algunas regiones que requieren de la intervención del Ejecutivo.

En los resultados a la fecha de presentación del presente trabajo, si bien muestran números muy superiores, se aprecian medidas y resultados que dan inicio a la cuarta fase. En efecto, mediante D.S. $N^{\circ} 156-2020-P C M$ se modifica el Decreto Supremo $N^{\circ} 116-2020-P C M$, Decreto supremo que establece las medidas que debe seguir la ciudadanía en la nueva convivencia social y prorroga el Estado de Emergencia Nacional por las graves circunstancias que afectan la vida de la Nación a consecuencia del COVID-19, modificado por los Decretos Supremos No 129-2020-PCM, No 135-2020PCM, No 139-2020-PCM, No 146-2020-PCM, № 151-2020-PCM, y se prorroga el estado de emergencia focalizándose aún más la inmovilidad social por el mes de octubre de 2020. Asimismo, por D.S. N 157-2020-PCM se aprueba la Fase 4 de la reanudación de actividades económicas dentro del marco de la declaratoria de Emergencia Sanitaria Nacional por las graves circunstancias que afectan la vida de la Nación a consecuencia del COVID-19 a partir del mes de octubre de 2020.

En tal sentido, los resultados se han mostrado alentadores, como el caso de las vacunas en etapa de prueba en humanos. Hechos, plazos y efectos positivos han generado una mayor apertura de las actividades económicas sin restringir las exigencias en los cuidados establecidos.

Empero, ha quedado claro que la sociedad anterior a la pandemia no tiene ninguna posibilidad de retorno. Actualmente se trata de explicar qué efectos beneficiarán generando cambios estructurales o de menor nivel y en qué medida ocasionará la perdida de actividades, organizaciones, relaciones sociales o de otro tipo.

\subsection{Efectos}

Los efectos que la pandemia declarada desde el 11 de marzo de 2020 ha desplegado sobre la sociedad global comprenden diversas dimensiones.

En Perú el Plano político deja ver una mayor intervención del Estado sobre la economía y el mercado que no pocas reacciones ha ocasionado. Desde un solitario reclamo desde el sector privado por la omisión en uno de los mensajes al Congreso de la República con referencia al apoyo de dicho sector, comenzó a mencionarse con mayor frecuencia dicho apoyo hasta el cambio de gabinete de vísperas del mensaje del 28 de julio de 2020.

En el ámbito social, al establecerse como parte de la lucha contra el coronavirus el aislamiento social obligatorio e inteligente y voluntario desde el 01 de julio de 2020, y, además, una serie de medidas que afectan las relaciones interpersonales y sociales, se ha notado una grave incidencia en el comportamiento individual y comunitario.

En el aspecto económico posiblemente es en donde, por sus efectos transversales, deja sentir con mayor énfasis sus incidencias negativas. El crecimiento económico se verá seriamente afectado este año y el próximo calculándose de modo optimista una caída del 15\% del PBI para el 2020. 
Los ámbitos que la pandemia afecta tienen relación directa con el que se pretende discutir en el presente. La gestión pública ha debido responder de modo eficiente, eficaz, efectivo, económico y, sobre todo, transparente. Atender, como deber del Estado, los efectos de la pandemia en los diversos ámbitos que demanda la población han constituido la labor de la Administración y ha debido adecuar su accionar a las exigencias de las necesidades que debió asistir.

El Estado subsidiario -como lo es el modelo establecido constitucionalmente- y bregar por un modelo de intervención mínima sin la suficiente claridad en sus alcances parecen haber pasado la factura. La respuesta a la pandemia por parte del Estado no fue suficiente en ninguno de sus aspectos. Nótese que no me refiero a la visible preocupación que se apreció, la puede resumirse como "mucha preocupación poca efectividad". Sucede que la Administración Pública constitucionalmente obligada a la prestación de servicios públicos fue sorprendida, por decir lo menos. Salud desbordada, educación menos que mediocre, seguridad con problemas de corrupción, comunicaciones y tecnologías a medias en el mejor de los casos.

En los derechos fundamentales de naturaleza social más importantes destaca el de contar con una buena Administración Pública (Muñoz, 2015, p. 51), dado que es la que asegura la eficacia del listado de los que reconoce la Constitución vigente. No olvidemos que, en cuanto a las deficiencias en los aspectos mencionados respecta, tratamos de derechos fundamentales no atendidos adecuadamente en una situación de crisis sanitaria pandémica atribuibles a la gestión pública.

Un hecho que resulta manifiestamente visible es la ausencia de políticas públicas para responder adecuadamente a situaciones de emergencia derivadas de pandemia. En efecto, no obstante la vigencia desde el 2013 del Decreto Legislativo № 1156 que dicta medidas destinadas a garantizar el servicio público de salud en los casos en que exista un riesgo elevado o daño a la salud y la vida de las poblaciones, específicamente para los supuestos de pandemias, y el Reglamento que regula las Políticas Nacionales Decreto Supremo № 029-2018-PCM de marzo de 2018 hasta el presente año, no se cuenta con la política pública que establezca ordenadamente la intervención de la Administración Pública del Estado en los supuestos de pandemias como la que ha generado la declaración de estado de emergencia sanitaria de 2020.

La ausencia de tal herramienta de gestión ha sido notoria y letal. Imprevisión, ineficiencia, ineficacia, derroche de recursos, anomia, responsabilidades imprecisas y la infaltable corrupción como corolario de todo lo anterior han sido las características de la gestión pública durante el periodo que viene desde el 11 de marzo de 2020 . En el primer consolidado de políticas públicas en materia de salud que hizo el CEPLAN a junio de 2019 no aparece ninguna que corresponda a la intervención del Estado en situación de pandemia. El orden y cumplimiento de las normas que se exigía a la población no era cumplido por la Administración Pública con los efectos devastadores que tiene el desorden. Similar situación se aprecia en el Sector Justicia y Derechos Humanos en donde no se pueden encontrar políticas públicas que regulen la intervención del Estado en materia de seguridad jurídica a través del Registro, las intervenciones vienen respondiendo a requerimientos o necesidades concretas y como respuesta a ellas.

Todo lo anterior puede asumirse como el shock que produjo el inicio de la pandemia y la serie de respuestas desde la Administración Pública destinadas a paliar sus efectos primigenios, en tanto que se desconocía el origen, estructura y efectos dañinos en la salud de la población del virus generador. El tiempo ocurrido ha servido 
para descubrir de qué se trata y cómo atacarlo, encontrándose actualmente resultados muy alentadores.

Sin embargo, cabe preguntarse: ¿qué efectos podemos esperar de la pandemia como sociedad global, en qué medida se verá afectada y modificada en su estructura y qué actores, empresas u organizaciones dejarán paso a nuevos participantes?

Virus, bacterias y seres humanos aparecen en ese orden en el tiempo, y las pandemias generadas por los primeros son recurrentes en la historia y han generado cambios estructurales y permanentes en la sociedad. En general podemos afirmar que han sido las crisis las que han generado los cambios que han hecho el mundo que actualmente conocemos. La peste negra en el siglo XIII fue seguida del renacimiento, la primera y segunda Guerra Mundial, seguida la gripe española, permitieron estructurar la sociedad en la que vivíamos antes de la pandemia. La gran pregunta es qué nos espera o hacia dónde debe encausarse la sociedad que queda luego de la pandemia. Se espera que se produzca un gran reinicio (Schwab y Malleret, 2020).

\section{Derecho fundamental a una buena Administración Pública}

\subsection{Antecedentes y Derecho Comparado}

La construcción normativa de este derecho fundamental parte desde recomendaciones, específicamente desde la recomendación (80) 2 de 11 de marzo de 1980, del Comité de Ministros del Consejo de Europa, de la jurisprudencia del Tribunal de Justicia de las Comunidades Europeas y del Tribunal de Primera Instancia.

En diciembre del año 2000 la Carta Europea de los Derechos Fundamentales incorpora expresamente este derecho. El artículo 41 de dicho instrumento normativo establece principios como la imparcialidad, equidad y plazo razonable, a ser oído, acceso al expediente, motivación en las decisiones, reparación por daños y uso de lenguaje; principios que deben tenerse en cuenta por la Administración Pública en su actuación. Estos alcances se encuentran comprendidos en el Código de Europeo de Buena Conducta Administrativa del año 1995. Si bien se trata de una especie de consolidado de principios ya reconocidos en el régimen administrativo, lo novedoso se encuentra en el reconocimiento como integrantes de un derecho fundamental.

Rodriguez-Arana concluyendo establece que el derecho fundamental a la buena administración pública en su relación con los ciudadanos exige que actúe de acuerdo con 24 principios reconocidos por el ordenamiento jurídico (Rodriguez-Arana, 2012, p. 269). Estos, igualmente, los podemos encontrar en nuestras normas que conforman el plexo normativo de Derecho Administrativo en el Perú.

En base al Derecho Comparado europeo podemos establecer que este Derecho fundamental debe comprender básicamente:

1. Trato imparcial, equitativo, justo, objetivo y plazos razonables por las entidades al servicio de la dignidad humana.

2. Ser oídos, acceso al expediente, motivación en las decisiones.

3. Reparación por daños.

4. Uso de la lengua propia al dirigirse o recibir respuesta de las entidades.

5. Complementariamente, el acceso a la información pública.

En el contexto americano, la Constitución Política de la Ciudad de México (2017), Artículo 12, establece el Derecho a la Buena Administración Pública, el mismo que se 
desarrolla en la Ley Constitucional de Derechos Humanos y sus Garantías de la Ciudad de México (2019) en su Artículo 36. Se regula que la buena administración pública tiene carácter receptivo, eficaz y eficiente y se rige por los principios generalidad, uniformidad, regularidad, continuidad, calidad. Asimismo, por el uso de TICs y de audiencia previa para actos privativos de autoridad, se resolverán los casos de modo imparcial, equitativo, en plazo razonable y con acceso al expediente.

En la República Dominicana por Ley 107-13, en su Artículo 4, se reconoce el derecho de las personas a una buena Administración Pública, derecho que se concreta en un catálogo de 34 derechos subjetivos de orden administrativo. No se trata de derechos fundamentales, en tanto que no los encontramos en la Constitución Política, sino en la Ley Orgánica mencionada. No obstante, ha sido el Tribunal Constitucional quien acoge la tesis de la existencia de tales derechos como fundamentales en función a derechos de carácter administrativo que se regulan en su Constitución Política, así lo expresa en la sentencia TC/0322/14.

Puede apreciarse que el derecho fundamental a la buena Administración Pública, expresamente establecido a nivel constitucional o recogido por el Tribunal Constitucional de los países latinoamericanos, se viene convirtiendo en una realidad en nuestro continente habiéndose recogido la experiencia europea en tan importante derecho fundamental.

La construcción de este nuevo derecho, comprensivo de otros que ya se encuentran regulados, debe fijarse de modo genérico en la norma constitucional remitiéndose a un desarrollo legislativo posterior.

\subsection{Formulación en el Derecho Constitucional Peruano}

El Estado Peruano se define jurídicamente por los alcances regulados en la Constitución Política de 1993. Se trata de una república democrática, social, independiente, soberana, con gobierno unitario y descentralizado. Entre sus deberes se encuentran los de garantizar y proteger los derechos humanos.

Desde los alcances mencionados, y tratándose de un Estado social de derecho, encontramos que la norma fundamental recoge las características que permiten identificarlo como tal: juricidad, división de poderes, respeto a los derechos humanos, solidaridad y participación.

A pesar de que se establece como deber del Estado la protección y garantía de los derechos humanos y fundamentales, no encontramos en su articulado una referencia expresa a la buena Administración Pública como tal, que puede exigirse como una petición de principio. Igualmente, no encontramos que el Tribunal Constitucional haya recurrido a dicho concepto para resolver causas contra la Administración Pública peruana.

Además, lo anterior ocurre no obstante que en la "Carta Iberoamericana de los Derechos y Deberes del Ciudadano en Relación con la Administración Pública" aprobada por el Consejo Directivo del CLAD el 10 de octubre de 2013, en cumplimiento del mandato recibido por la XV Conferencia Iberoamericana de Ministras y Ministros de Administración Pública y Reforma del Estado Ciudad de Panamá el 27 y 28 de junio de 2013 y adoptada por la XXIII Cumbre Iberoamericana de Jefes de Estado y de Gobierno Ciudad de Panamá del 18 y 19 de octubre de 2013, se establece en su Capítulo III, apartados del 25 al 46 partes pertinentes, el derecho fundamental a la buena Administración Pública y sus derechos derivados en los términos siguientes: 
"25. Los ciudadanos son titulares del derecho fundamental a la buena Administración Pública, que consiste en que los asuntos de naturaleza pública sean tratados con equidad, justicia, objetividad, imparcialidad, siendo resueltos en plazo razonable al servicio de la dignidad humana.

26. Derecho a la motivación de las actuaciones administrativas: todas las actuaciones de la Administración Pública deberán estar amparadas en razonamientos inteligibles para todo ciudadano acreditándose la objetividad que preside su entero y completo quehacer.

27. Derecho a la tutela administrativa efectiva: durante la sustanciación del procedimiento administrativo la Administración estará sometida plenamente a la Ley y al Derecho y procurará evitar que el ciudadano interesado pueda encontrarse en situación de indefensión.

28. Derecho a una resolución administrativa amparada en el ordenamiento jurídico, equitativa y justa, de acuerdo con lo solicitado y dictada en los plazos y términos que el procedimiento señale. En este sentido, las Autoridades administrativas deberán resolver los expedientes que obren en su poder en los plazos establecidos, los cuales a su vez deberán permitir una defensa jurídica adecuada de los ciudadanos, dando a conocer el tiempo máximo de resolución previsto, en el marco de los medios materiales y las dotaciones de personas con los que cuente en cada caso la Administración Pública.

29. Derecho a presentar por escrito o de palabra peticiones de acuerdo con lo que se establezca en las legislaciones administrativas de aplicación, en los registros físicos o informáticos. La forma de relación del ciudadano con la Administración Pública debe ser elegida por el propio ciudadano y facilitada por aquella. En caso de existir varias lenguas cooficiales en el país, se atenderá a lo dispuesto en el Ordenamiento Jurídico correspondiente. En todo caso la Administración Pública deberá asegurar la disposición de los medios más adecuados para personas con discapacidad.

30. Derecho a no presentar documentos que ya obren en poder de la Administración Pública, absteniéndose de hacerlo cuando estén a disposición de otras Administraciones públicas del propio país. Los ciudadanos tienen derecho a no presentar documentos cuando éstos se encuentren a disposición de la Administración Pública. Las posibilidades de intercomunicación a través de las TICS de los registros de las distintas Administraciones Públicas deben hacer posible que entre ellas se intercambien todos los documentos que obrando en su poder sean necesarios para que los ciudadanos tramiten sus solicitudes. Cada Organismo o ente público deberá arbitrar los medios necesarios para, en tiempo y forma, atender a este derecho sin descuidar las otras responsabilidades que resulten indelegables por la naturaleza de las funciones cumplidas.

31. Derecho a ser oído siempre antes de que se adopten medidas que les puedan afectar desfavorablemente.

32. Derecho de participación en las actuaciones administrativas en que tengan interés, especialmente a través de audiencias y de informaciones públicas. Los ciudadanos tendrán derecho a participar, a tenor de lo dispuesto en la Carta Iberoamericana de Participación Ciudadana en la Gestión Pública, 
en los procedimientos de elaboración de disposiciones de carácter general, de acuerdo con lo dispuesto en el ordenamiento jurídico correspondiente.

33. Derecho a servicios públicos y de interés general de calidad.

En observación en lo que dispone la Carta Iberoamericana de Calidad en la Gestión Pública, los servicios de responsabilidad pública deben ofrecer a los usuarios determinados patrones o estándares concretos de calidad, que se medirán periódicamente y se pondrán en conocimiento de los usuarios para que estos estén lo mejor informados posible y puedan efectuar los comentarios y sugerencias que estimen pertinentes.

34. Derecho a conocer y a opinar sobre el funcionamiento y la calidad de los servicios públicos y de responsabilidad administrativa para lo cual la Administración Pública propiciará el uso de las TICS.

35. Derecho a formular alegaciones en el marco del procedimiento administrativo. Con independencia de las audiencias e informaciones públicas que estén previstas en el ordenamiento jurídico correspondiente, los ciudadanos interesados podrán formular las alegaciones que estimen pertinentes, siempre que estén convenientemente argumentadas, de acuerdo con el procedimiento administrativo.

36. Derecho a presentar quejas y reclamaciones ante la Administración Pública. Los ciudadanos también tendrán derecho a presentar recursos contra actos o resoluciones de la Administración Pública de acuerdo con los correspondientes ordenamientos jurídicos.

37. Derecho a conocer las evaluaciones de gestión que hagan los entes públicos y a proponer medidas para su mejora permanente de acuerdo con el ordenamiento jurídico correspondiente. Los ciudadanos podrán ser consultados periódicamente sobre su grado de satisfacción con los servicios que reciben de la Administración Pública, a través de encuestas, sondeos y demás instrumentos apropiados para ello.

38. Derecho de acceso a la información pública y de interés general, así como a los expedientes administrativos que les afecten en el marco del respeto al derecho a la intimidad y a las declaraciones motivadas de reserva que habrán de concretar el interés general en cada supuesto en el marco de los correspondientes ordenamientos jurídicos. Se facilitará el ejercicio de este derecho mediante medios electrónicos a través de portales de transparencia y acceso a la información de interés general.

39. Derecho a copia sellada de los documentos que presenten a la Administración Pública. Todo ciudadano, con el fin de iniciar un procedimiento administrativo o una determinada solicitud a la Administración Pública con todas las garantías, recibirá copia sellada de tal actuación ante las Administraciones Públicas. La copia sellada se le facilitará en medios físicos o electrónicos dependiendo del medio escogido para el inicio del procedimiento o realización de la solicitud.

40. Derecho de ser informado y asesorado en asuntos de interés general. Los ciudadanos tienen derecho a que quienes laboran en las oficinas públicas de atención al ciudadano establecidas para tal fin les asesoren e informen cordialmente acerca de los trámites u otras cuestiones de interés 
general. En dichas oficinas debe haber organigramas de los entes públicos que pertenezcan al ámbito administrativo ya sea de forma material o virtual. Los ciudadanos tienen el derecho a que en las resoluciones desfavorables consten los medios de impugnación que el ordenamiento jurídico pone a su alcance, con expresa mención de los plazos y consecuencias jurídicas de la interposición de tales reclamaciones o recursos.

41. Derecho a ser tratado con cortesía y cordialidad. Toda persona tiene derecho a un trato digno por quienes laboran en las dependencias públicas. Todo ciudadano que se encuentre en situación de pobreza, indefensión, debilidad manifiesta, discapacidad, niños, niñas, adolescentes, mujeres gestantes o adultos mayores tendrán derecho a recibir un trato especial y preferente, por parte de las autoridades, agentes y demás personal al servicio de la Administración Pública, quienes deben facilitarles todo lo posible para el acceso a las oficinas públicas, la orientación adecuada y los servicios que soliciten.

42. Derecho a conocer el responsable de la tramitación del procedimiento administrativo. Cuando se inicia un procedimiento administrativo, en la copia sellada que se entrega al ciudadano interesado se procurará hacer constar, por medios físicos o electrónicos según corresponda, de acuerdo con el Ordenamiento jurídico respectivo, la identidad del servidor público responsable de la tramitación de dicho expediente, a quien el ciudadano podrá dirigirse en los horarios establecidos al efecto.

43. Derecho a conocer el estado de los procedimientos administrativos que les afecten. El funcionario responsable de la tramitación del procedimiento estará a disposición del ciudadano interesado para informarle en cada momento de la situación del expediente administrativo, sea oralmente, por escrito o a través de las TICS.

44. Derecho a ser notificado por escrito en los plazos y términos establecidos en las disposiciones correspondientes y con las mayores garantías, de las resoluciones que les afecten.

45. Derecho a participar en asociaciones o instituciones de usuarios de servicios públicos o de interés general.

46. Derecho a exigir el cumplimiento de las responsabilidades de las personas al servicio de la Administración Pública y de los particulares que cumplan funciones administrativas de acuerdo con el ordenamiento jurídico respectivo. Los ciudadanos, además del derecho a exigir la justa indemnización en plazo razonable por la lesión que puedan sufrir en sus bienes o derechos a causa del funcionamiento de los servicios públicos o de interés general, en los casos en que así se determine de acuerdo con el ordenamiento jurídico correspondiente, podrán demandar, ante la Administración y/o ante los Jueces o Tribunales, las responsabilidades en que puedan haber incurrido los servidores públicos en el ejercicio de sus funciones."

Asimismo, en dicho documento se desarrolla en su Capítulo cuarto: Los deberes del ciudadano iberoamericano en relación con las administraciones públicas, apartados 47 a 53 estableciéndose con los siguientes alcances: 
"47. Los ciudadanos, en sus relaciones con las Administraciones Públicas, tienen, correlativamente con sus derechos, sendos deberes y obligaciones, que son, entre otros, los que se exponen en los siguientes preceptos.

48. Lealtad. Los ciudadanos deberán acatar con lealtad la Constitución, las Leyes así como el entero ordenamiento jurídico con arreglo a las exigencias de un Estado de Derecho.

49. Buena fe. Los ciudadanos habrán de actuar siempre de acuerdo con el principio de buena fe, tanto en el uso de la información obtenida de la Administración Pública, la cual deberá ser utilizada con interés legítimo, como así también abstenerse del uso de maniobras dilatorias en todo procedimiento 0 actuación en relación con dicha Administración Pública.

50. Veracidad. Los ciudadanos tienen la obligación de ser veraces en todas sus relaciones con la Administración Pública, evitando toda afirmación o aportación falsa o temeraria a sabiendas.

51. Responsabilidad. Los ciudadanos deben ejercer con la máxima responsabilidad los derechos que les reconoce el ordenamiento jurídico, absteniéndose de reiterar solicitudes improcedentes o impertinentes 0 de presentar acciones que representen erogaciones innecesarias de los recursos del Estado.

52. Respeto y decoro. Los ciudadanos observarán en todo momento un trato respetuoso con las autoridades, funcionarios y con todo el personal al servicio de la Administración Pública.

53. Colaboración. Los ciudadanos deberán colaborar siempre y en todo momento al buen desarrollo de los procedimientos y actuaciones administrativas, cumpliendo diligentemente todas las obligaciones razonables y justas que les impone el ordenamiento jurídico, especialmente en materia tributaria, reconociendo los costos establecidos para la atención demandada."

La protección procesal del derecho a una buena Administración Pública y sus derechos que lo componen se regula en el capítulo quinto, apartado 54, estableciéndose que "tendrán la protección administrativa y jurisdiccional de los derechos humanos previstos en los diferentes ordenamientos jurídicos" (Carta Iberoamericana de los Derechos y Deberes del Ciudadano en Relación con la Administración Pública, 2013).

El derecho a una buena Administración Pública se trata de un derecho fundamental de amplia difusión en Europa y en países como México y República Dominicana; sin embargo, aún no es regulado en nuestro país ni ha sido recogido por la Jurisprudencia Constitucional. Se trata de un derecho fundamental en espera de tal reconocimiento en beneficio de los ciudadanos y en razón a lo indicado en la Carta Iberoamericana citada.

\subsection{Derechos fundamentales afectados}

Se declaró en el Perú la emergencia sanitaria el 11 de marzo de 2020 como consecuencia de la declaración de pandemia del coronavirus realizada por la OMS. No siendo suficiente tal medida, el 15 de marzo de 2020 se declara el estado de emergencia mediante Decreto Supremo N 044-2020-PCM. Esta último, con mayores restricciones, 
evidentemente lleva implícita la afectación de la vigencia de algunos derechos fundamentales.

En los fundamentos expresados en los considerandos de la norma expedida $(E I$ Peruano, 15 de marzo de 2020) se señala que el Artículo 44 de la Carta Magna prevé que son deberes primordiales del Estado garantizar la plena vigencia de los derechos humanos, proteger a la población de las amenazas contra su seguridad; asimismo, se invoca el numeral 1 del Artículo 137 del referido texto, en cuanto se establece que el Presidente de la República, con acuerdo del Consejo de Ministros, puede decretar por plazo determinado en todo el territorio nacional, o en parte de él, dando cuenta al Congreso o a la Comisión Permanente, el Estado de Emergencia, entre otros, en caso de graves circunstancias que afecten la vida de la Nación, pudiendo restringirse o suspenderse el ejercicio de los derechos constitucionales relativos a la libertad y la seguridad personales, la inviolabilidad de domicilio, y la libertad de reunión y de tránsito en el territorio.

Más aún, coexistiendo el estado de emergencia con la emergencia sanitaria declarada, debemos entender que además de la restricción o suspensión de los derechos fundamentales mencionados, debe considerarse lo expresado en los argumentos de la declaración de la emergencia sanitaria Decreto Supremo $\mathrm{N}^{\circ} 008$ 2020-SA el 11 de marzo de 2020 cuando mencionan a la Ley № 26842, Ley General de Salud, en su numeral XII del Título Preliminar en donde prevé que:

"el ejercicio del derecho a la propiedad, a la inviolabilidad del domicilio, al libre tránsito, a la libertad de trabajo, empresa, comercio e industria, así como el ejercicio del derecho de reunión, están sujetos a las limitaciones que establece la ley en resguardo de la salud pública" (Ley General de Salud).

En consecuencia, dada la coexistencia del estado de emergencia y de emergencia sanitaria, no solo se restringen o suspenden el ejercicio de los derechos constitucionales relativos a la libertad y la seguridad personales, la inviolabilidad de domicilio, y la libertad de reunión y de tránsito en el territorio, sino que además la propiedad, libertad de trabajo, empresa, comercio e industria quedan sujetos a las limitaciones que establece la ley en resguardo de la salud pública.

\subsection{Administración y Gestión Pública peruana}

El Estado actúa a través de su maquinaria administrativa. Todas las entidades integrantes de la Administración Pública se encuentran involucradas con la actuación del poder estatal. Sus decisiones son la expresión de la voluntad concreta del Estado.

El criterio que se utilice y las particularidades que se muestren en el ámbito definido para alcances normativos específicos mantienen a la actuación de la Administración Pública como parte fundamental del crecimiento e índice de la productividad con la que aporta a dicho indicador.

En la contratación, ámbito penal, procedimental, presupuestario, etcétera. encontramos la delimitación del ámbito de lo que debemos entender por Administración Pública. Más o menos entidades las integrantes de dicho ámbito asumiremos la que corresponde al ámbito procedimental que regula de modo general la actuación de las entidades. Es decir, entendemos que el ámbito comprensivo de la Administración Pública está definido en la Ley $\mathrm{N}^{\circ} 27444$, reguladora de la expresión concreta de la voluntad estatal. En este aspecto es de precisar que constituirá parte de la Administración Pública en tanto desarrollen función administrativa. 
La actuación de las entidades de la Administración Pública se manifiesta a través de decisiones públicas. Estas no pueden constituirse en arbitrarias, imprevistas, desordenadas, desarticuladas, sin horizonte que permita prever hacia dónde vamos. Por ello es que los componentes de toda decisión pública responden a dos campos: las políticas y la gestión públicas.

La forma como el Estado interviene en la solución de problemas sociales se refleja en las políticas públicas. Estas se definen como formas de intervención de la Administración Pública en el ejercicio de la función administrativa, vale decir, la atención de los problemas sociales a través del Poder Ejecutivo. El Decreto Supremo N 0292018-PCM constituye el Reglamento de las políticas públicas que busca el orden en la actuación de la Administración Pública en la atención de los problemas sociales. Las políticas públicas se aprueban mediante la norma de mayor nivel que expide el Poder Ejecutivo, es decir a través de Decreto Supremo y con un contenido actualmente pautado.

Por su parte, la gestión pública constituye la forma como se realiza la actuación, concepto dinámico de la Administración Pública y concepto estructural. Se busca que la actuación o gestión de las entidades respondan a la formulación de políticas públicas que constituyen el modo de ordenarla y de fijarle horizontes que respondan a aquellos que como Estado se buscan alcanzar. En este sentido el crecimiento es básico, como condición para el desarrollo. Con ello, la atención ordenada de problemas sociales para crecer y desarrollarnos. Tal parece ser el fin de regular las decisiones del Estado a través de su maquinaria administrativa. Conceptos estrechamente vinculados con la situación de pandemia y de emergencia sanitaria actual que hacen apreciar la necesidad de un derecho de nivel constitucional que proteja a la persona del accionar de la Administración Pública.

\subsection{La competitividad}

La Administración Pública en su ámbito estructural y desde su actuación, teniendo como herramientas las políticas públicas, busca su competitividad; es decir, lograr crecer ordenadamente y siendo productivos para generar un círculo virtuoso que nos lleve al desarrollo y prosperidad.

La competitividad y sus elementos se definen por el Foro Económico Mundial (WEF) (Cann, 2020) como el conjunto de instituciones, políticas y factores que determinan el nivel de productividad de un país. Competitividad es productividad, esta conduce como factor principal al crecimiento y al bienestar real. En suma, la competitividad debe entenderse como la forma con que el Estado promueve nuestro bienestar real.

La productividad está vinculada a las instituciones que la influyen decisivamente. Por definición, las instituciones forman parte de los elementos que deben considerarse en la productividad y, en consecuencia, en la competitividad de un país. Las instituciones sirven para medir la competitividad, constituyen uno de sus subíndices o pilares básicos. Se establecen como aquellos conceptos relacionados con la protección de los derechos de propiedad, eficiencia y transparencia de la Administración Pública, independencia del Poder Judicial, seguridad física, ética de negocios y gobierno corporativo, y pueden ser públicas o privadas.

Lo anterior fácilmente nos conduce a apreciar la vinculación del SINARP y de la SUNARP con la productividad del país, considerando que tiene vinculación directa con 
la protección de los derechos de propiedad. Más aún en una situación de emergencia sanitaria con aislamiento social y cuarentena obligatoria, en donde la publicidad jurídica debe sustituir necesariamente a un sistema de publicidad como la posesión. Asimismo, siendo entidad de la Administración Pública, se encuentra estrechamente relacionada con su eficiencia y transparencia. Del mismo modo, siendo un sistema de publicidad jurídica constituye una de las formas como el Estado reduce la asimetría en la información del mercado, con ello fundamentalmente facilita y asegura las transacciones (costos de transacción).

Para obtener una idea clara de la competitividad de nuestro país debemos establecer comparaciones adecuadas, vale decir con países en similar situación. Sucede que en nuestro ámbito debemos hacerlo con quien lidera el ranking WEF de competitividad 2020, es decir, Chile (Rodríguez, 2020).

En el 2008 el Perú ocupó el puesto 35 de 55, logrando su mejor ubicación. La caída ha sido sostenida, y se encuentra actualmente en el puesto 52 de 63 países, según muestra un segundo ranking que para el capítulo peruano elabora la PUCP (CENTRUMPUCP, 2020). El factor en el que más destaca es en eficiencia del gobierno; sin embargo, de los indicadores que lo integran el marco institucional, ocupa el tercer lugar de 05 con 48.3 puntos para el 2020, subiendo desde 37.1 el 2018. Sobre un puntaje total de 100 , el indicador que nos interesa no alcanza nota aprobatoria. Al respecto, debe tenerse en cuenta que se toma como fortaleza el impacto de las políticas del Banco Central de Reserva (BCR) en la economía, en tal sentido como entidad debe considerarse como referente la performance del BCR. Asimismo, debe tenerse en cuenta que las debilidades continúan siendo el soborno y la corrupción, economía paralela y días de apertura de un negocio, indicadores en los que sí tiene algo que decir la SUNARP.

En el indicador respecto a la eficiencia del gobierno, Chile continúa liderando el grupo. Se ubica en el puesto $20^{\circ}$ con 72.1 puntos, escalando seis posiciones y aumentando alrededor de 5.2 puntos con relación al año pasado. Perú ocupa el segundo lugar de la región, ubicándose en el puesto $40^{\circ}$, escalando 9 posiciones y aumentando en 2.7 puntos respecto del año 2019.

En este estado del análisis cabe preguntarse qué hace Chile y qué dejamos de hacer nosotros para tener las ubicaciones que mencionamos.

Como país, Chile se muestra como un destino atractivo para la recepción de inversión extranjera directa; asimismo, cuenta con las mejores credenciales para el comercio internacional y, en cuanto a la brecha digital, se encuentra mejor posicionado que casi la totalidad de los países de la región, supuestos que lo posicionan en su protagonismo hacia un nuevo reto constituido por el desarrollo inclusivo que se convierte en un paso más allá de la competitividad y productividad.

Con la concepción general desarrollada sobre competitividad y vista la situación de uno de nuestros vecinos como mejor referente, veamos qué sucede en el nuestro. Para ello debemos tener en cuenta que si bien se concibe que la recuperación económica depende (Stiglitz, 2020) del control sobre el COVID-19 y la prioridad la tiene la política fiscal sobre la salud, todas las entidades se ven requeridas a actuar competitivamente.

En el Acuerdo Nacional encontramos como tercera política de Estado la competitividad, así como diversas normas desde el nivel constitucional tratan de vincularse con ella. En función a ello, por Decreto Supremo № 345-2018-EF del 31 de 
diciembre de 2018, se aprobó la Política Nacional de Competitividad y Productividad y por Decreto Supremo No 237-2019-EF del 28 de julio de 2019 el plan nacional correspondiente. En estos instrumentos normativos expresamente se reconoce la vinculación entre productividad y competitividad y, asimismo, se adopta una concepción estructuralista del concepto de competitividad y se interpreta como la capacidad que tiene una nación para competir exitosamente en los mercados, a través de la utilización eficiente de sus recursos naturales renovables y no renovables y el aprovechamiento de sus ventajas comparativas, generando, así, bienestar compartido.

La protección de los derechos de propiedad, en el marco institucional de la productividad y competitividad de un país, constituyen una institución recurrente y en este ámbito es en donde la SUNARP tiene bastante que hacer. Desde la protección misma y las medidas colaterales para su logro que viene realizando responden a necesidades concretas, siendo en esto en donde se aprecia la necesidad de articular la performance con políticas nacionales que definan el tipo de registro jurídico que mejor serviría a tal propósito. Una buena Administración Pública tendría como exigencia de primer orden el ser competitiva desde el ámbito que le corresponda actuar.

En tanto lo anterior no ocurra, el esfuerzo desplegado continuará siendo paliativo a la prestación de un servicio sin mayor efectividad que la que se procura lograr desde el tipo de registro que tenemos.

Si bien el ámbito registral es secundario al que involucra a la propiedad como institución, es decir el Derecho Civil, no debe perderse de vista que se viene pensando en que la presente crisis generará cambios estructurales, pudiendo ser uno de ellos o ambos en donde puedan producirse los cambios estructurales mencionados.

\section{Registros jurídicos}

\subsection{Seguridad jurídica en el sistema constitucional peruano}

La situación en la que quedan algunos derechos fundamentales, como la propiedad, por la declaración de emergencia sanitaria motiva a tratar el tema del presente apartado. Desde las posibilidades de establecer limitaciones por parte del Estado hasta aquellos derechos de propiedad cuya custodia se encuentran a cargo de la SUNARP o cuyo acceso pretendan, se tiene directa vinculación con la seguridad jurídica.

La seguridad jurídica no es un concepto que el ordenamiento constitucional peruano defina. Sin embargo, sus manifestaciones, condiciones, características, dimensiones, elementos -o cualquier otra denominación que se pretenda otorgarpodemos encontrarlas sistémicamente en el articulado de la constitución.

En tal sentido $-\mathrm{y}$ siguiendo las condiciones o dimensiones de la seguridad jurídica desarrollada por Pérez Luño (1994)-, analizaremos el contenido de la Constitución Política del Perú vigente desde 1993. No obstante, debemos dejar constancia de la inclusión de la positividad del Derecho como una dimensión básica y punto de partida de la seguridad jurídica, posición con la que discrepa el autor citado.

Estructural y funcionalmente encontramos elementos regulados en la Constitución vigente que permiten concebir a la seguridad jurídica.

En cuanto a la primera, pueden considerarse dimensiones ligadas a la técnica legislativa como la promulgación (lege promulgata). En cuanto a las normas jurídicas de 
cualquier nivel, debemos entenderla como un mandato destinado a que todas las normas deben ser conocidas por todos. En tal sentido, la propia Constitución Política de 1993, luego de ser sancionada, aprobada o dada por el Congreso Constituyente, debió ser promulgada por el Presidente de la República para su cumplimiento por todos. En cuanto a normas infra constitucionales, la Constitución, en su Artículo 108, establece que:

"La ley aprobada según lo previsto por la Constitución, se envía al Presidente de la República para su promulgación dentro de un plazo de quince días. En caso de no promulgación por el Presidente de la República, la promulga el Presidente del Congreso, o el de la Comisión Permanente, según corresponda. Si el Presidente de la República tiene observaciones que hacer sobre el todo o una parte de la ley aprobada en el Congreso, las presenta a éste en el mencionado término de quince días. Reconsiderada la ley por el Congreso, su Presidente la promulga, con el voto de más de la mitad del número legal de miembros del Congreso" (Constitución Política del Perú, 1993).

Con la promulgación se manda publicar y cumplir condiciones para su vigencia, como se establece en el artículo 109 de la norma fundamental: "la ley es obligatoria desde el día siguiente de su publicación en el diario oficial, salvo disposición contraria de la misma ley que posterga su vigencia en todo o en parte" (Constitución Política del Perú, 1993). La promulgación o puesta en conocimiento del texto normativo se constituye en una dimensión básica del sistema jurídico, su inexistencia invalida cualquier disposición.

Otra dimensión que puede integrarse en este primer grupo es la claridad y precisión (lege manifiesta, chiare e precise), es decir las normas jurídicas deben eludir la ambigüedad, términos equívocos u oscuros, evitándose, de esta forma, la excesiva discrecionalidad. Esta es una condición de la libertad jurídica definida en el artículo 2 inciso 24 en el que se establece que toda persona tiene derecho "a la libertad y a la seguridad personales. En consecuencia: a. Nadie está obligado a hacer lo que la ley no manda, ni impedido de hacer lo que ella no prohíbe." El mandato de claridad y precisión en los alcances normativos establece el ámbito de reserva personal inexigible. Por el contrario, consecuencia de la regla anterior, la Administración Pública requiere del mandato expreso de norma legal para actuar (reserva legal). Además, las exigencias anteriores se complementan con su contraria en cuanto a exigencia Plenitud (lege plena) evitando las lagunas legales y jurídicas.

La exigencia para la Administración Pública, en su artículo 118, establece que corresponde al Presidente de la República: "Ejercer la potestad de reglamentar las leyes sin transgredirlas ni desnaturalizarlas; y, dentro de tales límites, dictar decretos y resoluciones". Se da de esta forma plenitud a nuestro sistema jurídico, no dejando lugar a la absoluta discrecionalidad la solución de los conflictos jurídicos. Se cubren, de este modo, las tres funciones básicas y generales, directas o por delegación, del Estado: legislativa, ejecutiva y judicial. Dos dimensiones adicionales que proporcionan seguridad al sistema jurídico las constituyen la irretroactividad (lege previa) y estabilidad (lege perpetua).

En el aspecto funcional se consideran dimensiones como la garantía del cumplimiento del Derecho (destinatarios) y la regularidad de la actuación de la Administración Pública, sujeta siempre al principio de legalidad. La eficacia del Derecho se encuentra íntimamente vinculada con el aspecto funcional. El ámbito estructural de la seguridad jurídica no garantiza su eficacia. El cumplimiento requiere de la puesta en movimiento en esa dirección de la maquinaria operativa del Estado, es decir de la Administración Pública en su integridad y de modo coherente. 
Tratamos en este aspecto de las entidades de la Administración Pública en su totalidad y de quienes ejercen la función pública. Al respecto el artículo 39 de la Constitución establece que "todos los funcionarios y trabajadores públicos están al servicio de la Nación. El Presidente de la República tiene la más alta jerarquía en el servicio a la Nación y, en ese orden, los representantes al Congreso, ministros de Estado, miembros del Tribunal Constitucional y del Consejo de la Magistratura, los magistrados supremos, el Fiscal de la Nación y el Defensor del Pueblo, en igual categoría; y los representantes de organismos descentralizados y alcaldes, de acuerdo a ley."

De lo anterior apreciamos que la seguridad jurídica es un concepto integrado en la Constitución Política vigente y una obligación ineludible de la Administración Pública en su totalidad. Más aún, corresponde a las entidades que se caracterizan por asegurar instituciones como los derechos de propiedad, en este caso la SUNARP.

\subsection{Ciudadanía digital y tecnologías como auxilio}

La exigencia de protección o seguridad jurídica de los derechos de propiedad y, entre otros, el de contar con una buena Administración Pública cuyo ejercicio debe realizarse a través de medios digitales ha generado un nuevo concepto que pasamos a tratar.

En los tiempos de pandemia y post-pandemia ha quedado firme el convencimiento de que las TICs no constituyen más un espacio complementario en el desenvolvimiento social. Se ha entendido, sobre todo por la sociedad, que los nuevos medios son una forma eficiente y efectiva de empoderamiento, convirtiéndose en una exigencia luego de haberse mostrado reticencias a su aceptación.

La ubicuidad, dinamicidad y apertura de las redes terminó imponiéndolas con la vigencia de las medidas de confinamiento. No hubo alternativa, su utilidad se impuso y las ha llevado sino al principal a un plano de igualdad con la presencialidad. No queda duda, sí, que se quedarán sin ningún inconveniente como una forma de optimizarla.

Las nuevas herramientas virtuales proporcionan participación y empoderan a la ciudadanía, pero no la aseguran. Se empodera en tanto que les permiten conseguir objetivos y promover sus intereses; sin embargo, la seguridad, sobre todo jurídica, requiere poco más que lo anterior. Tratamos ello sobre todo desde un aspecto muy importante como la protección de los derechos de propiedad, institución fundamental en temas de competitividad como país.

Desde hace varios años existen estudios (Cáceres Zapatero, 2015) que demuestran la relación entre las nuevas tecnologías y el empoderamiento social, que pueden utilizarse de manera horizontal y colaborativa, aun cuando ello no se manifestaba en un efectivo control sobre los poderes públicos.

La participación de los individuos en la Internet y TICs ha llevado a que terminen ejerciendo sus derechos civiles y políticos por medio de dichas herramientas, lo que ha generado la aparición del concepto de ciudadanía digital (Alva de la Selva, 2020, p. 83), y que a su vez se comiencen a forjar comunidades digitales o virtuales con influencia en la reorganización de lazos sociales y en la estimulación de la democracia.

En el país, el surgimiento y desarrollo de la ciudadanía digital se produce por la confluencia de una multiplicidad de factores, es decir, de aspectos políticos, económicos, sociales, tecnológicos, etcétera. 
El principal de los derechos fundamentales de carácter social, insistimos, es el de contar con una buena Administración Pública. En este sentido la ciudadanía digital juega un importantísimo papel, haciendo valer el derecho fundamental respecto de la propiedad. No debemos perder de vista que los registros jurídicos tienen como núcleo o centro de su regulación los derechos de propiedad, institución fundamental para medir o acreditar el nivel o grado de productividad en un país. En tal sentido, el ejercicio de la ciudadanía digital puede ir destinada a hacer valer una mayor protección a tal derecho y exigir seguridad jurídica desde su base, la titulación auténtica, hasta los efectos que produce la inscripción. Ello implica tener en cuenta los límites de lo digital y los alcances de la presencialidad. En el primer país en el ranking mundial, Estonia, la presencialidad para disposición de derechos de propiedad aún se mantiene, así como para temas como matrimonio y divorcio.

El país ya cuenta con una plataforma digital que integra a toda la Administración Pública (gob.pe), asimismo se cuenta con un régimen de gobierno digital con la dación del Decreto Legislativo № 1412 y los Decretos de Urgencia Nº6-2020 y Nº7-2020, sobre creación del sistema nacional de transformación y confianza digitales respectivamente. La política pública nacional y la estrategia que oriente la gestión ha sido referida en el último discurso presidencial.

Lo anterior indica que la SUNARP debe orientarse hacia la transparencia, participación y colaboración en un entorno digital dentro de la cuarta revolución industrial anunciada en el último lustro. El cambio cultural y de mentalidad parecen haber sido anunciados como una necesidad y con carácter de urgentes por la situación actual.

\subsection{Los Registros jurídicos}

Por Ley N²6366 del 14 de octubre de 1994 se crea en el Perú el Sistema Nacional de los Registros Públicos (SINARP), con la finalidad, como se indica en el artículo 1 de dicha ley, de proporcionar unidad y coherencia al ejercicio de la función registral. Se busca con la creación del sistema la especialización, simplificación, integración y modernización de la función, procedimientos y gestión. EI SINARP integró jurídicamente y en el aspecto registral los Registros que se encontraban dispersos en los diferentes sistemas funcionales de la Administración Pública. Comprende cuatro grandes grupos: Registros de personas naturales, jurídicas, bienes muebles y de la propiedad inmueble.

El ente rector del SINARP es, de acuerdo con la Ley $\mathrm{N}^{\circ} 26366$, la Superintendencia Nacional de los Registros Públicos (SUNARP) Organismo técnico especializado adscrito al Sector Justicia. Esta entidad cuenta con personería jurídica de Derecho Público y sobre todo con autonomía en los siguientes aspectos: funcional, jurídico registral, técnica, económica, financiera y administrativa.

Las funciones más importantes con las que cuenta la SUNARP son la dación de las políticas y normas técnico-administrativas de los Registros Públicos. En tal sentido, resulta competente para planificar, organizar, normar, dirigir, coordinar y supervisar la inscripción y publicidad.

Lo anterior permite afirmar que en la Ley $N^{\circ} 26366$ antes referida, el Registro es concebido desde tres acepciones: como Oficina, entidad pública que gestiona el sistema; como conjunto de libros, las técnicas registrales utilizadas desde los tomos hasta los medios electrónicos que se desarrollan en el Reglamento General de los 
Registros Públicos (RGRRPP); y como institución jurídica, es decir, todo el plexo normativo referido a las dos acepciones anteriores.

Como Oficina, entidad que se encarga de su gestión, la Superintendencia cuenta con una Administración básica conformada por los órganos, según denominación que aparece en la ley de creación, de la Alta Dirección, las Gerencias Legal y de Informática y la Oficina de Control Interno, cuyas funciones se especifican en su Reglamento de Organización y Funciones en el que a su vez se modifican algunas denominaciones de los órganos mencionados. A nivel nacional, la SUNARP cuenta con Órganos desconcentrados -denominados Zonas Registrales- que actualmente llegan a ser 14.

La gestión del sistema de registros jurídicos antes referido, caracterizados por la seguridad jurídica que proporcionan a los derechos de propiedad como parte de la Administración Pública, debe ser apreciada desde el nivel de protectora de derechos fundamentales. En efecto, la concepción mencionada debe comprender el derecho a una buena Administración Pública, así como a la protección de los derechos de propiedad.

En tal sentido, como derecho fundamental a una buena Administración Pública, el ente rector del sistema registral debe responder a las expectativas ciudadanas y convertirse además en el facilitador de la gestión y acceso a la protección que proporciona haciendo que la seguridad jurídica se convierta en parte integrante de los bienes cuyos derechos asegura. De este modo, los bienes, los derechos de propiedad sobre ellos y la seguridad jurídica se convierten en conceptos "tangibles" y cercanos al ciudadano. Las tecnologías digitales o las que las reemplacen constituirán las herramientas que faciliten dicho empeño.

La gestión del sistema registral ya cuenta con suficiente experiencia y con una cultura en gobierno electrónico que posibilita y facilita el transito al gobierno digital. Posiblemente constituya una de las entidades mejor dotadas para realizar este cambio sin mayores inconvenientes.

\section{Conclusiones}

1. El estado de emergencia sanitaria se ha generado por eventos atípicos que han demandado los mayores esfuerzos de la Administración Pública. Las necesidades se vienen atendiendo en conformidad con los avances que la investigación científica proporciona y con los recursos del crecimiento sostenido del país durante las últimas décadas.

2. Se establece que los efectos de la pandemia son multidimensionales. Efectos políticos, sociales, económicos y administrativos han quedado evidenciados. En el ámbito administrativo los servicios públicos se vieron desbordados por los nuevos y abundantes requerimientos de la población.

3. La necesidad de mayores y oportunos servicios públicos precisa de una buena Administración Pública permanentemente exigible por parte del ciudadano. En tal sentido, la competitividad de la gestión pública queda evidenciada como elemento fundamental para el alcance integral de los servicios públicos, debiendo proveerse de herramientas de gestión como las políticas públicas y el gobierno digital para obtener resultados satisfactorios.

4. La buena Administración Pública se ha regulado como derecho fundamental en el Derecho Comparado. De este modo resulta necesario precisar sus exigencias y 
alcances y regularla como derecho fundamental para dotarla de exigibilidad en nuestro régimen normativo.

5. La gestión del sistema de registros jurídicos se vio igualmente afectada por la pandemia. La declaración de emergencia suspendió sus servicios vinculados básicamente con la seguridad jurídica y afectó derechos fundamentales vinculados con la propiedad. Ello evidenció la relevancia del referido sistema dentro de la Administración Pública; asimismo, dejó apreciar su inmediata respuesta a los requerimientos de los administrados.

6. Empero, lo anterior, deja abierta la posibilidad de la definición de un nuevo tipo de registro jurídico a regularse con el reconocimiento de los derechos de propiedad como articuladores de un nuevo sistema.

\section{Referencias:}

Alva de la Selva, A. R. (2020). Escenarios y desafíos de la ciudadanía digital en México. Revista Mexicana de Ciencias Políticas y Sociales, 65(238), 81-105. https://doi.org/10.22201/fcpys.2448492xe.2020.238.68337

Banco Mundial (12 de abril de 2020). https://www.bancomundial.org. Obtenido de https://www.bancomundial.org:

http://documents1.worldbank.org/curated/en/555821593587247371/pdf/The-

Economy-in-the-Time-of-COVID-19.pdf

Cáceres Zapatero, M. (2015). Hacia la construcción de una ciudadanía digital. Prisma social - No 15. 643-684.

Cann, O. (26 de julio de 2020). https://es.weforum.org. Obtenido de https://es.weforum.org/agenda: https://es.weforum.org/agenda/2016/10/que-esla-competitividad/

CENTRUMPUCP. (26 de julio de 2020). https://centrumthink.pucp.edu.pe. Obtenido de https://centrumthink.pucp.edu.pe/indices/competitividad/:

https://centrumthink.pucp.edu.pe/resultados-del-ranking-de-competitividadmundial-2020

El Peruano (15 de marzo de 2020). Decreto Supremo 044-2020-PCM. Declaran estado de emergencia a nivel nacional. Editora Perú.

Muñoz, J. R.-A. (mayo-agosto de 2015). Dimensiones del Estado Social y derechos fundamentales sociales. Revista de Investigações Constitucionais, 2 (2). https://doi.org/10.5380/rinc.v2i2.44510(2), 31-62.

Organización Mundial de la Salud [OMS] (06 de julio de 2020). https://www.who.int/es. Obtenido de https://www.paho.org/es/documentos-tecnicos-ops-enfermedadpor-coronavirus-COVID-19: https://www.paho.org/es/tag/informes-situacionCOVID-19

Organización Mundial de la Salud [OMS] (11 de marzo de 2020). https://www.who.int/es. Obtenido de https://www.who.int/es/: https://www.who.int/es/dg/speeches/detail/who-director-general-s-openingremarks-at-the-media-briefing-on-COVID-19---11-march-2020

Perez Luño, A. E. (1994). La seguridad jurídica. Ariel S.A.

Rodríguez, C. (26 de julio de 2020). https://es.weforum.org. Obtenido de https://es.weforum.org/agenda: https://es.weforum.org/agenda/2018/10/quehace-que-chile-sea-la-economia-mas-competitiva-de-america-latina-f05ff0e2ef94-4d5c-b019-9fb0234b2bc3/

Rodriguez-Arana, J. (2012). El derecho a la buena administración en las relaciones entre ciudadanos y Administración Pública. Anuario da Facultade de Dereito da Universidade da Coruña, 247-274.

Schwab, K. y Malleret T. (2020). COVID-19: El Gran reinicio. Forum Publishing. 
Stiglitz, J. (26 de julio de 2020). https://es.weforum.org. Obtenido de https://es.weforum.org/agenda: https://es.weforum.org/agenda/2020/07/josephstiglitz-sobre-las-prioridades-para-la-economia-post-COVID/ 